\title{
PERLINDUNGAN HUKUM PEKERJA RUMAH TANGGA DALAM HUBUNGAN KERJA PENUH WAKTU
}

\author{
Luh Eni Pribadi, I Nyoman Putu Budiartha, Desak Gde Dwi Arini \\ Fakultas Hukum Universitas Warmadewa, Denpasar - Bali, Indonesia
}

\begin{abstract}
Abstrak
Pekerja Rumah Tangga (PRT) merupakan seseorang yang memiliki tugas pokok dan fungsi seperti mencuci, memasak, membersihkan rumah, mengasuh anak majikan dan berbagai tugas lain yang diberikan oleh majikannya. Penelitian ini bertujuan untuk menganlisis bentuk perlindungan hukum Pekerja Rumah Tangga dalam Hubungan Kerja Penuh Waktu dan mengetahui peran Lembaga Penyalur Pekerja Rumah Tangga (LPPRT) dalam Hubungan Kerja Penuh Waktu menurut PERMENAKER RI Nomor 2 Tahun 2015. Metode yang digunakan dalam penelitian ini yaitu metode normatif, dengan bersumber pada bahan hukum primer dan sekunder. Hasil penelitian menunjukan bahwa bentuk perlindungan hukum pekerja rumah tangga telah dituangkan dalam peraturan Menteri Ketenagakerjaan Nomor 2 Tahun 2015, sebagai upaya untuk memberikan perlindungan bagi pekerja rumah tangga, untuk memenuhi hak - hak nya sebagai pekerja. Kemudian, peran lembaga penyalur pekerja rumah tangga adalah sebagai perantara untuk mempertemukan pekerja dengan majikan, lembaga memiliki kewajiban untuk menyeleksi calon majikan agar PRT tidak jatuh ke tangan yang salah, lembaga juga harus memeriksa pekerja apakah pekerja merupakan orang yang baik dan jujur sehingga tidak ada pihak yang dirugikan. Melalui penelitian ini diharapkan kepada pemerintah khususnya bidang Ketenagakerjaan lebih mensosialisasikan Peraturan Mentri Ketenagakerjaan Nomor 2 Tahun 2015 agar tidak terjadi kekerasan kepada Pekerja Rumah Tangga. Selain itu, dalam mencegah terjadinya hal-hal yang tidak diinginkan kepada pekerja rumah tangga, hendaknya lembaga penyalur lebih memperhatikan pekerja yang disalurkan, lebih mendalami latar belakang dan asal usul dari calon majikan, mengawasi pekerja rumah tangga dengan cara menanyakan bagaimana keadaannya dan bagaimana majikannya memperlakukan PRT baik melalui sambungan telepon maupun surat.
\end{abstract}

Kata Kunci: Pekerja Rumah Tangga; Pekerja penuh waktu; Perlindungan Hukum

\begin{abstract}
Abstrak
A household assistant is someone who has basic duties and functions such as washing, cooking, cleaning the house, caring for the employer's child and various other tasks assigned by the employer. This study aims to analyze the form of legal protection of domestic workers in full-time employment relationships and find out the role of the Domestic Workers Distribution Agency in Full-time Work Relationships according to the Republic of Indonesia PERMENAKER No. 2 of 2015. The method used in this study is the normative method, sourced from primary and secondary legal materials. The results show that the form of legal protection for domestic workers has been set forth in the regulation of the Minister of Manpower Number 2 of 2015, as an effort to provide protection for domestic workers, to fulfill their rights as workers. Then, the role of the domestic worker supplier agency is as an intermediary to bring workers and employers together, the institution has the obligation to select prospective employers so that domestic workers do not fall into the wrong hands, the institution must also examine workers whether the workers are good and honest people so that no party who is harmed. Through this research, it is hoped that the government, especially in the field of Manpower, will further socialize the Minister of Manpower Regulation No. 2 of 2015 so that there is no violence against domestic workers. In addition, in preventing the occurrence of undesirable things to domestic workers, the channeling institution should pay more attention to the workers who are being dispatched, be more in depth with the background and origin of the prospective employer, supervise domestic workers by asking how the situation is and how the employer treats Domestic workers both by telephone and mail.
\end{abstract}

Keywords: Domestic Workers; Full-time workers; Legal protection 


\section{PENDAHULUAN}

Pekerja Rumah Tangga (PRT) telah ada sejak lama, diperkirakan ada sejak zaman kerajaan, penjajahan, begitu pula sesudah Indonesia Merdeka. Saat ini asisten rumah tangga telah berkembang dan mengalami perubahan orientasi dari hubungan kekerabatan menjadi hubungan pekerjaan, apalagi di kota-kota besar pekerjaan pekerja rumah tangga sangat dibutuhkan. Pekerja rumah tangga adalah bagian dari masyarakat yang tidak berdaya di tengah modernisasi. Pekerja rumah tangga bekerja dalam lingkup rumah tangga yang sangat privat, dimana aturan main di setiap rumah tangga berbedabeda, sehingga harus bisa mengikuti aturan main dalam keluarga majikan, jika ingin tetap bertahan di rumah tersebut.

Biasanya pekerja rumah tangga yang bekerja di salurkan oleh teman, tetangga atau bahkan saudaranya sendiri, sehingga tidak memiliki kontrak kerja. Kesepakatan kerja yang terjadi hanya secara lisan disampaikan, dengan saling memahami peran masing-masing. Ketidak jelasan jenis kerja, jam kerja, dan upah yang diterimanya sejak awal menjadi pemicu munculnya berbagai permasalahan. Sementara untuk pekerja rumah tangga yang disalurkan melalui Lembaga Penyalur Pekerja Rumah Tangga (LPPRT) kontrak kerja, yang terjadi bukan antara pekerja rumah tangga tetapi antara majikan dan penyalur, sehingga pekerja rumah tangga menjadi obyek untuk diperjual belikan oleh Lembaga Penyalur Pekerja Rumah Tangga (LPPRT) yang nakal.

Dalam mengorganisir Pekerja Rumah Tangga (PRT) bukanlah sesuatu yang mudah, mengingat pekerja rumah tangga berada di ranah orang lain. Dimana dan untuk apapun yang akan dilakukan asisten rumah tangga, dia harus mendapatkan ijin terlebih dahulu dari majikannya.

Memang harus diakui bahwa sampai saat ini Pekerja Rumah Tangga (PRT) sebagai pekerja tidak diterima oleh semua pihak. Pekerja Rumah Tangga (PRT) tidak diakui sebagai tenaga kerja yang sama dengan tenaga kerja lainnya seperti pekerja pabrik, perusahaan, dan lain-lain. Bahkan harus diakui bahwa dewasa ini sebutan sebagai "Pekerja" pun belum diterima oleh masyarakat. Pada umumnya masyarakat lebih menerima untuk menyebut Pekerja Rumah Tangga (PRT) sebagai "pembantu". Oleh karena itu, Pekerja Rumah Tangga (PRT) dimasukkan dalam lingkup pekerjaan sektor informal. Dengan memasukkan Pekerja Rumah Tangga (PRT) dalam lingkup sektor informal, perjuangan untuk mendapatkan hak-hak pekerja terbatas. Hal ini karena persoalan-persoalan Pekerja Rumah Tangga (PRT) tidak tercakup dalam ketentuan perundang-undangan mengenai ketenagakerjaan yang berlaku. Pekerja Rumah Tangga (PRT) tidak mendapatkan perlindungan hukum yang menjamin pekerjaan mereka sama seperti rekan-rekan mereka yang bekerja di pabrik, perusahaan, dan lain-lain.

Didalam Undang-undang tentang ketenagakerjaan No 13 Tahun 2003 didalam Pasal 1 butir 3 telah mendefinisikan apa yang dimasud dengan pekerja/buruh. Berdasarkan pengertian tersebut nampak bahwa seharusnya PRT termasuk dalam pekerja sektor formal yang dilindungi oleh ketentuan undang-undang. Pada sektor ketenagakerjaan, eksistensi PRT tidak dimasukkan kategori pekerjaan pada instasi-instansi pemerintah maupun swasta. Oleh karena itu PRT dimasukkan ke dalam ruang lingkup informal. Sektor informal yang diisi jenis kerja domestik PRT rentan terhadap berbagai tindak kekerasan dan tentunya membutuhkan perlindungan ekstra dari negara1. Kelemahan atau kekurangan acuan yuridis ini memberikan dampak bahwa PRT kurang mendapatkan perlindungan hukum. Adanya pengakuan secara sosial dan hukum tentunya akan memudahkan dalam membuat peraturan perundang-undangan yang secara langsung memberikan perlindungan kepada para Pekerja Rumah Tangga (PRT). Maka, acuan yuridispun menjadi jelas bagi Pekerja Rumah Tangga (PRT) dan pengguna jasa Pekerja Rumah Tangga (PRT) serta masyarakat.

Beberapa penelitian sebelumnya telah mengkaji masalah tentang wanita yang bekerja sebagai pembantu rumah tangga, seperti Erna Wati (2014); Hidayati (2014). Dari hasil penelitian itu dikatakan bahwa Pekerja Rumah Tangga (PRT) adalah kelompok marginal yang paling rentan terhadap kelalaian yang dilakukan oleh majikan. Oleh sebab itu, perlindungan hukum juga sangat penting untuk melindungi kaum PRT dari kekerasan. Selanjutnya, Gani (2016) mengatakan bahwa hak-hak wanita dalam bekerja yaitu perlindungan jam kerja, perlindungan dalam masa haid, perlindungan selama cuti hamil dan melahirkan, pemberian lokasi menyusui, perlindungan kesehatan dan keselamatan kerja perempuan, dan perlindungan upah. Kemudian, Dhewy (2017); Sonhaji (2020) menyatakan bahwa walaupun kebanyakan pekerja rumah tangga berpendidikan rendah maka mereka harus tetap mendapakat perlindungan hukum oleh negara supaya diskrimanasi, kekerasan dan pengabaian hak untuk pekerja rumah tangga dapat dilaksanakan dengan baik. 
Keberadaan PERMENAKER RI No.2 Tahun 2015 tentang Perlindungan Pekerja Rumah Tangga (PRT) merupakan peraturan yang sangat penting untuk memberikan jaminan kepastian hukum kepada para Pekerja Rumah Tangga (PRT) dalam memperoleh hak-hak mereka dan melaksanakan kewajiban mereka. Tentunya hal ini berlaku juga bagi para pengguna jasa yang mempekerjakan Pekerja Rumah Tangga (PRT). Kedua belah pihak dapat terhindar dari penyalahgunaan kekuasaan dalam hubungan kerja di antara Pekerja Rumah Tangga (PRT) dan pengguna jasanya. Mengingat banyaknya kasus kekerasan yang di alami oleh pekerja rumah tangga yang dilakukan oleh majikannya yang salah satunya terjadi di Bali, Eka Febriyanti yang bekerja sebagai PRT, mengalami kekerasan yang dilakukan oleh majikannya, nasib nahas itu dialami perempuan asal Jember, Jawa Timur, yang bekerja di rumah Desak Made Wiratningsih, Eka kerap mengalami kekerasan fisik hingga psikis. Kepala hingga tubuhnya disiram air mendidih sebanyak dua panci serta tak digaji selama bekerja untuk Desak Made Wiratningsih2. Oleh Karena itu, berdasarkan latar belakang masalah yang telah di bahas di atas, maka penelitian ini bertujuan untuk menganlisis bentuk perlindungan hukum Pekerja Rumah Tangga dalam Hubungan Kerja Penuh Waktu dan mengetahui peran Lembaga Penyalur Pekerja Rumah Tangga (LPPRT) dalam Hubungan Kerja Penuh Waktu menurut PERMENAKER RI Nomor 2 Tahun 2015

\section{METODE PENELITIAN}

Penelitian ini didesain dengan menggunakan pendekatan hukum empiris. Adapun sumber bahan hukum yang digunakan dalam penelitian ini yaitu bahan hukum peraturan perundang-undangan yakni KUHPerdata, UU Nomor 13 Tahun 2003 tentang Ketenagakerjaan, Peraturan Mentri Ketenagakerjaan Nomor 2 Tahun 2015 tentang Perlindungan Pekerja Rumah Tangga. Kemudian, bahan hukum sekunder yaitu bahan hukum yang diperoleh dari pengkajian kepustakaan (Library research) yaitu dengan membaca buku- buku hukum, jurnal-jurnal hukum, surat kabar dan juga dari internet yang berkaitan dengan dalam permasalahan yang di teliti. Teknik pengumpulan bahan hukum yang digunakan dalam penelitian ini adalah teknik dokumentasi yang dilaksanakan dengan cara menginventarisasi dan mengkatagorisasi bahan-bahan hukum seperti peraturan perundang-undangan, literatur - literatur maupun bahan hukum lainnya.

\section{HASIL PENELITIAN DAN PEMBAHASAN}

\section{Hubungan Kerja Penuh Waktu bagi Pekerja Rumah Tangga dengan LPPRT}

Hubungan kerja penuh waktu bagi pekeja rumah tangga merupakan, pekerja yang memiliki waktu kerja yang panjang karena kebutuhan anggota keluarga yang tidak memiliki batas tertentu. pada dasarnya , bekerja untuk pihak lain dengan harapan akan mendapatkan imbalan atas pekerjaanya, sebagaimana pengertian pekerja berdasarkan ketentuan perundang-undangan (Aloysius, 2014). Hubungan kerja sebagai bentuk hubungan hukum yang lahir setelah adanya perjanjian antara pekerja dengan lembaga, perjanjian yang dibuat tidak boleh bertentangan dengan peraturan Perundang undangan. LPPRT atau lembaga penyalur memiliki tugas untuk menyalurkan tenaga kerja kepada seorang yang membutuhkan tenaga kerja khususnya di bidang Pekerja Rumah Tangga. Lembaga penyalur tenaga kerja harus cakap dalam hukum dan lembaga penyalur telah memiliki izin dan tidak bertentangan dengan hukum (Shofia, 2016). Manfaat adanya lembaga penyalur tenaga kerja adalah:

1. Manfaat bagi pemerintah, dapat mengurangi pengangguran karena lembaga membantu orang untuk mencari pekerjaan dan ditampung di lembaga tersebut dan dilatih khususnya dalam bidang pekerjaan rumah.

2. Memudahkan untuk mencari tenaga kerja sesuai dengan keinginannya. Bahwa untuk mendirikan suatu perusahaan lembaga penyalur tenaga kerja wajib memiliki izin operasional seperti yang dijelaskan pada Pasal 1 point 5 Peraturan Menteri Nomer 2 tahun 2015, harus meiliki Surat Ijin Usaha dari Gubernur atau instansi yang bertanggungjawab sesuai dengan domisilinya. Berdirinya LPPRT sesuai dengan ketentuan yang berlaku maka calon pencari kerja dan calon penerima jasa tidak akan dirugikan dan tidak akan terlibat dalam penipuan karena sudah memiliki izin operasional.

Adanya sebuah hubungan kerja maka didalamnya pasti terdapat perjanjian kerja. Perjanjian adalah perbuatan hukum berdasarkan kata sepakat yang menentukan akibat hukum (Budiartha, 2016). Dalam hubungan antara pekerja dengan lembaga penyalur tentu saja ditandai dengan adanya perjanjian. Berdasarkan hasil wawancara penulis salah satu lembaga penyalur pekerja rumah tangga di Denpasar yang bernama Yayasan Teratai, dalam perjanjian mengenai pekerja dengan lembaga 
menyebutkan upah pertama dari pekerja harus dibayarkan ke yayasan, sedangkan upah selanjutnya akan dibayar langsung kepada pekerja. Yayasan Teratai ini menerima calon pekerja usia diatas 17 tahun, dan melakukan pelatihan sebelum disalurkan. Perjanjian kerja menurut Pasal 1601a KUHPerdata adalah suatu persetujuan, bahwa pihak kesatu, yaitu pekerja, mengikatkan diri untuk menyerahkan tenaganya kepada pihak lain, yaitu pengusaha, dengan upah selama waktu tertentu (Sayid, 2017).

Adapun unsur - unsur perjanjian kerja yang menjadi dasar hubungan kerja sesuai dengan ketentuan Pasal 1 ayat (4) Undang - undang Nomor 13 Tahun 2003 adalah:

1. Adanya pekerjaan.

2. Di bawah perintah.

3. Adanya upah tertentu.

4. Dalam waktu.

Dalam hubungan hukum antara pekerja dengan agen perusahaan, pengsaha merupakan orang yang memberi kuasa yang wajib membayar, sedangkan agen perusahaan adalah orang yang menerima kuasa yang wajib menjalankan kekuasaan yang diberikan oleh pemberi kuasa (Abdulkadir, 2010).

\section{Peran Lembaga Penyalur Pekerja Rumah Tangga (LPPRT) dalam Hubungan Kerja Penuh Waktu.}

Lembaga penyalur memiliki peran untuk mempertemukan pencari kerja dengan pemberi kerja yang sesuai dengan kebutuhan dan pemberi kerja memberikan imbalan berupa gaji dari hasil kerjanya. Dengan adanya lembaga penyalur tenaga kerja memberikan peluang kerja bagi yang membutuhkan dengan meninjau kembali sesuai dengan mekanisme perekrutan, penempatan dan perlindungan. Dalam peraturan Mentri Nomor 2 Tahun 2015 Tentang Perlindungan Pekerja Rumah Tangga Pasal 9 adapun persyaratan yang harus dilakukan oleh pengguna jika ingin mendapatkan PRT. Persyaratan Pengguna:

a. Mempunyai penghasilan yang tetap

b. Memiliki tempat tinggal yang layak.

c. Sehat jasmani dan rohani.

Lembaga penyalur juga memiliki kewajiban yang diatur dalam Pasal 23:

a. Menyeleksi calon pengguna.

b. Memastikan calon PRT dalam keadaan yang sehat dan dapat bekerja dengan baik.

c. Memonitor PRT yang telah disalurkan pada pengguna.

d. Mengembalikan imbalan jasa

Dalam perjanjian antara Yayasan Teratai dengan pihak majikan, menyatakan pihak yayasan hanya membantu memberikan identitas pekerja yang disalurkan. Tenaga kerja yang telah disalurkan menjadi tanggungjawab majikan.

Yayasan tersebut tidak sepenuhnya dapat melindungi pekerja yang disalurkan, kepala yayasan tersebut hanya mengatakan cara menyeleksi calon pekerja dan penerima jasa melalui sifat dan tingkah lakunya. Yayasan juga tidak bertanggungjawab apabila pekerja memiliki hutang, memakai telepon, dan mencuri di rumah majikannya, dan apabila PRT sakit maka pihak majikan yang membiayai pengobatannya. Hasil wawancara yang dilakukan pada tanggal 4 Maret 2020 terhadap Yayasan Teratai kekurangannya adalah :

1. Tidak dapat melindungi sepenuhnya pekerja rumah tangga.

2. Tidak dapat bertanggungjawab apabila PRT mengalami masalah dengan majikannya.

3. Cara untuk melihat ke gigihan dan kejujuran dari Pekerja hanya 3 hari sebelum pekerja disalurkan.

4. Tidak ada perjanjian khusus antara Yayasan dengan pekerja yang disalurkan, perjanjian antara yayasan dengan pekerja menggunakan perjanjian lisan, memberikan pengarahan untuk bersikap baik dan jujur kepada majikan.

Kelebihan dari Yayasan Teratai menurut hasil wawancara adalah:

1. Yayasan tidak memperkejakan anak di bawah umur, minimal batas usia calon PRT adalah 17 (tujuh belas tahun).

2. Memberikan pergantian pekerja/PRT apabila tidak ada kecocokan dengan majikan.

3. Memeriksa identitas majikan melalui KTP, mencaritahu apa pekerjaanya dan memiliki tempat tinggal yang layak. 
4. Syarat untuk pengguna/calon majikan pada saat pengambilan pekerja melalui perjanjian tertulis dengan yayasan.

5. Memperbolehkan siapa saja yang memerlukan pekerjaan atau sedang mencari kerja ke yayasan tersebut asalkan identitasnya lengkap dan tidak di bawah umur, mulai dari 17 (tujuh belas) tahun sampai 60 (enam puluh) tahun.

Tidak jarang antara pekerja dengan majikan tidak membuat perjanjian dengan majikan, ILO (Internasional Labour Organization) merangkum kejahatan- kejahatan yang terjadi terhadap majikan seperti pemeutusan hubungan kerja yang tidak adil seperti akibat sakit, kehamilan, tidak adanya jaminan sosial. Kasus-kasus kriminalisasi mencakup tuduhan - tuduhan palsu dan penganiayaan, serta kasus - kasus perdagangan manusia.

Menurut ILO PRT memiliki hak hukum yang sama ditempat kerja, seperti para pekerja dan profesi lainnya. Meski PRT memiliki peran penting mereka masih tidak diakui sebagai pekerja. PRT mewakili kelompok pekerja perempuan terbesar yang bekerja didalam rumah tangga baik di dalam negeri maupun luar negeri. Saat ini ILO memperkirakan terdapat sekitar 2.6 Juta PRT di Indonesia diantaranya anak dibawah umur 17 (tujuh belas) Tahun.

Pekerja rumah tangga sangat rentan terhadap tindakan kekerasan dan pelecehan. Sebagai pekerja informal mereka tidak memiliki payung hukum yang kuat jika mengalami ketidakadilan oleh majikannya, masyarakat seharusnya bisa menjadi aktor penggerak dengan memperlakukan PRT sebagai pekerja yang sederajat dan memperlakukan PRT sebagai profesi yang mulia.

\section{SIMPULAN DAN SARAN}

\section{Simpulan}

Bentuk perlindungan hukum pekerja rumah tangga telah dituangkan dalam peraturan Menteri Ketenagakerjaan Nomor 2 Tahun 2015, sebagai upaya untuk memberikan perlindungan bagi pekerja rumah tangga, untuk memenuhi hak - hak nya sebagai pekerja. Untuk pekerja penuh waktu yang tinggal bersama majikannya, majikan harus memiliki rumah yang layak untuk pekerja agar pekerja merasa aman dan terlindungi. Peran lembaga penyalur pekerja rumah tangga adalah sebagai perantara untuk mempertemukan pekerja dengan majikan, lembaga memiliki kewajiban untuk menyeleksi calon majikan agar PRT tidak jatuh ke tangan yang salah, lembaga juga harus memeriksa pekerja apakah pekerja merupakan orang yang baik dan jujur agar tidak ada pihak yang dirugikan.

\section{Saran}

Melalui penelitian ini diharapkan kepada pemerintah khususnya bidang Ketenagakerjaan lebih mensosialisasikan Peraturan Mentri Ketenagakerjaan Nomor 2 Tahun 2015, mengingat banyak yang tidak mengetahui peraturan tersebut, khususnya kepada pengguna PRT, terkadang pengguna PRT berlaku seenaknya kepada pekerja, maka dari itu pemerintah harus mensosialisasikan Peraturan Menteri Ketenagakerjaan tersebut, agar tidak lagi terjadi kekerasan dan hal - hal yang tidak diinginkan kepada PRT. Selain itu, dalam mencegah terjadinya hal-hal yang tidak diinginkan kepada pekerja rumah tangga, hendaknya lembaga penyalur lebih memperhatikan pekerja yang disalurkan, lebih mendalami latar belakang dan asal usul dari calon majikan, mengawasi pekerja rumah tangga dengan cara menanyakan bagaimana keadaannya dan bagaimana majikannya memperlakukan PRT baik melalui sambungan telepon maupun surat, PRT juga perlu diawasi bilamana PRT melakukan halhal yang tidak diinginkan seperti mencuri barang milik majikannya, lembaga juga harus memiliki perjanjian khusus dengan pekerja yang berisi hal-hal yang tidak diperbolehkan dilakukan di rumah majikannya agar pekerja dengan majikan memiliki hubungan yang baik. Kemudian, kepada masyarakat sangat diharapkan untuk berhenti memandang bahwa bekerja sebagai PRT merupakan hal yang tidak mulia, semua pekerja memiliki hak dan perlindungan yang sama.

\section{DAFTAR PUSTAKA}

Abdulkadir. (2010). Hukum Perusahaan Indonesia. Bandung: PT. Citra Aditya Bakti. Aloysius. (2014). Asas-Asas Hukum Perburuhan. Jakarta: Rajawali Pers.

Budiartha. (2016). Hukum Outsourcing. Malang: Setara Press.

Dhewy, A. (2017). Diskriminasi, Kekerasan dan Pengabaian Hak: Status PRT di Tengah Ketiadaan Payung Hukum Perlindungan PRT. Jurnal Perempuan: Untuk Pencerahan Dan Kesetraan, 22(3), 261-271. 
Erna Wati, B. (2014). Dimensi-Dimensi PerlinDungan Hukum bagi Pekerja Rumah Tangga di Era Industrialisasi. Palastren, 7(1), 153-168.

Gani, E. S. (2016). Hak Wanita Dalam Bekerja. Jurnal Tahkim, XII(1), 110-123.

Hidayati, N. (2014). Perlindungan terhadap Pembantu Rumah Tangga (PRT) Menurut Permenaker No. 2 Tahun 2015. Ragam Jurnal Pengembangan Humaniora, 14(3), 213-217.

Sayid. (2017). Hukum Ketenagakerjaan. Bandung: PT. Refika Aditama.

Shofia. (2016). Kebijakan Hukum Pidana Dalam Upaya Perlindungan Terhadap Anak yang Bekerja di Perusahaan. Jakarta: Dipenogoro Law Jurnal.

Sonhaji. (2020). Perlindungan Pekerja Rumah Tangga Dalam Sistem Hukum Nasional. Administrative Law \& Governance Journal, 3(2), 250-259.

Kitab Undang - Undang Hukum Perdata

Undang - Undang Nomor 13 Tahun 2003 Tentang Ketenagakerjaan

Peraturan Menteri Ketenagakerjaan Nomor 2 Tahun 2015 Tentang Perlindungan Pekerja Rumah Tangga 